\title{
A brief history of the antibiotic era: lessons learned and challenges for the future
}

\author{
Rustam I. Aminov* \\ Rowett Institute of Nutrition and Health, University of Aberdeen, Aberdeen, UK
}

\section{Edited by:}

Jose L. Martinez, Centro Nacional de

Biotecnología, Spain

Reviewed by:

Morten Otto Alexander Sommer,

Technical University of Denmark,

Denmark

Jose L. Martinez, Centro Nacional de

Biotecnología, Spain

*Correspondence:

Rustam I. Aminov, Rowett Institute of

Nutrition and Health, University of

Aberdeen, Aberdeen AB21 9SB, UK

e-mail: r.aminov@abdn.ac.uk
This article gives a very brief overview of the antibiotic era, beginning from the discovery of first antibiotics until the present day situation, which is marred by the emergence of hard-totreat multiple antibiotic-resistant infections. The ways of responding to the antibiotic resistance challenges such as the development of novel strategies in the search for new antimicrobials, designing more effective preventive measures and, importantly, better understanding the ecology of antibiotics and antibiotic resistance are discussed. The expansion of conceptual frameworks based on recent developments in the field of antimicrobials, antibiotic resistance, and chemotherapy is also discussed.

Keywords: history of antibiotic discovery, antibiotic resistance, novel antimicrobials, prevention of antibiotic resistance, environmental resistome

\section{ANTIBIOTICS AND ANTIBIOTIC RESISTANCE IN THE PRE-ANTIBIOTIC ERA}

Antimicrobials are probably one of the most successful forms of chemotherapy in the history of medicine. It is not necessary to reiterate here how many lives they have saved and how significantly they have contributed to the control of infectious diseases that were the leading causes of human morbidity and mortality for most of human existence. Contrary to the common belief that the exposure to antibiotics is confined to the modern "antibiotic era," research has revealed that this is not the case. The traces of tetracycline, for example, have been found in human skeletal remains from ancient Sudanese Nubia dating back to 350-550 CE (Bassett et al., 1980; Nelson et al., 2010). The distribution of tetracycline in bones is only explicable after exposure to tetracycline-containing materials in the diet of these ancient people. Another example of ancient antibiotic exposure is from a histological study of samples taken from the femoral midshafts of the late Roman period skeletons from the Dakhleh Oasis, Egypt (Cook et al., 1989). These samples showed discrete fluorochrome labeling consistent with the presence of tetracycline in the diet at that time (Cook et al., 1989). The postulated intake of tetracycline in these populations possibly had a protective effect because the rate of infectious diseases documented in the Sudanese Nubian population was low, and no traces of bone infection were detected in the samples from the Dakhleh Oasis (Armelagos, 1969; Cook et al., 1989).

Tetracyclines are unique among antibiotics in that they are strong chelators and are incorporated into the hydroxyapatite mineral portion of bones as well as tooth enamel and thus provide permanent markers of metabolically active areas during tetracycline exposure. Traces of exposure to other antibiotics in ancient populations are much more difficult to detect, and only surviving customs and anecdotal evidence may point to these occurrences. For example, anecdotes about the antibiotic-like properties of red soils in Jordan that were used historically (and are still being used as an inexpensive alternative to pharmaceutical products today) for treating skin infections have led to the discovery of a number of antibiotic-producing bacteria and concomitant antibiotic production in these soils (Falkinham et al., 2009). The actinomycete bacteria isolated from these soils produced actinomycin C2 and actinomycin $\mathrm{C} 3$, which are polypeptide antibiotics that bind to a pre-melted DNA conformation present within the transcriptional complex (Sobell, 1985) and, as such, have very little chance to be preserved in ancient samples.

Another possibility of exposure to antimicrobials in the preantibiotic era could be through the remedies used for millennia in traditional/alternative medicine, in particular in traditional Chinese medicine (TCM). The best-known example is the discovery of a potent anti-malarial drug, qinghaosu (artemisinin), which was extracted in the 1970s from Artemisia plants, used by Chinese herbalists for thousands of years as a remedy for many illnesses (Cui and $\mathrm{Su}, 2009)$. Antimicrobial activity seems present in a number of other herbs used in TCM (Wong et al., 2010) and the discovery of active components in these ancient remedies may enrich the arsenal of antimicrobials used by the mainstream medicine. At the same time, selective pressures imposed by these antimicrobial activities during the long-term history of TCM may have been one of the factors contributing to the accumulation of antibiotic resistance genes in human populations.

The natural history of antibiotic resistance genes can be revealed through the phylogenetic reconstruction and this kind of analysis suggests the long-term presence of genes conferring resistance to several classes of antibiotics in nature well before the antibiotic era (Aminov and Mackie, 2007; Kobayashi et al., 2007). Structure-based phylogeny of serine and metallo- $\beta$-lactamases, for example, established that these ancient enzymes originated more than two billion years ago, with some serine $\beta$-lactamases being present on plasmids for millions of years (Hall and Barlow, 2004; Garau et al., 2005). Phylogeny of the $\beta$-lactamase and housekeeping genes is highly congruent in Klebsiella oxytoca implying that these genes have been evolving for over 100 million years in this host (Fevre et al., 2005). 
The similar phylogenetic analysis of $\beta$-lactamases in the metagenomic clones derived from the 10,000 years old "cold-seep" sediments indicated that most of the diversity of these enzymes is not the result of recent evolution, but is that of ancient evolution (Song et al., 2005).

\section{FOUNDATION OF THE ANTIBIOTIC ERA}

We usually associate the beginning of the modern "antibiotic era" with the names of Paul Ehrlich and Alexander Fleming. Ehrlich's idea of a "magic bullet" that selectively targets only disease-causing microbes and not the host was based on an observation that aniline and other synthetic dyes, which first became available at that time, could stain specific microbes but not others. Ehrlich argued that chemical compounds could be synthesized that would "be able to exert their full action exclusively on the parasite harbored within the organism." This idea led him to begin a large-scale and systematic screening program (as we would call it today) in 1904 to find a drug against syphilis, a disease that was endemic and almost incurable at that time. This sexually transmitted disease, caused by the spirochete Treponema pallidium, was usually treated with inorganic mercury salts but the treatment had severe side effects and poor efficacy. In his laboratory, together with chemist Alfred Bertheim and bacteriologist Sahachiro Hata, they synthesized hundreds of organoarsenic derivatives of a highly toxic drug Atoxyl and tested them in syphilis-infected rabbits. In 1909 they came across the sixth compound in the 600th series tested, thus numbered 606, which cured syphilis-infected rabbits and showed significant promise for the treatment of patients with this venereal disease in limited trials on humans (Ehrlich and Hata, 1910). Despite the tedious injection procedure and side effects, the drug, marketed by Hoechst under the name Salvarsan, was a great success and, together with a more soluble and less toxic Neosalvarsan, enjoyed the status of the most frequently prescribed drug until its replacement by penicillin in the 1940s (Mahoney et al., 1943). Amazingly, the mode of action of this 100-year-old drug is still unknown, and the controversy about its chemical structure has been solved only recently (Lloyd et al., 2005).

The systematic screening approach introduced by Paul Ehrlich became the cornerstone of drug search strategies in the pharmaceutical industry and resulted in thousands of drugs identified and translated into clinical practice, including, of course, a variety of antimicrobial drugs. During the earlier days of antibiotics research, this approach led to the discovery of sulfa drugs, namely sulfonamidochrysoidine (KI-730, Prontosil), which was synthesized by Bayer chemists Josef Klarer and Fritz Mietzsch and tested by Gerhard Domagk for antibacterial activity in a number of diseases (Domagk, 1935). Prontosil, however, appeared to be a precursor to the active drug, and the active part of it, sulfanilamide, was thus not patentable as it had already been in use in the dye industry for some years. As sulfanilamide was cheap to produce and off-patent, and the sulfanilamide moiety was easy to modify, many companies subsequently started mass production of sulfonamide derivatives. The legacy of this oldest antibiotic on market is possibly reflected in one of the most broadly disseminated cases of drug resistance: sulfa drug resistance, which is almost universally linked with class

${ }^{1}$ http://pubs.acs.org/cen/coverstory/83/8325/8325salvarsan.html
1 integrons. Moreover, once the sulfa drug resistance is established on a mobile genetic element, it may be difficult to eliminate because the resulting construct confers a fitness advantage to the host even in the absence of antibiotic selection (Enne et al., 2004). Despite this, many continuously modified derivatives of this oldest class of synthetic antibiotics are still a viable option for therapy, and the action of and resistance to sulfanilamide is one of the best examples for the arms race between man and microbes. Two other classes of synthetic antibiotics successful in clinical use are the quinolones, such as ciprofloxacin, and oxazolidinones, such as linezoild (Walsh, 2003).

Probably many of us are familiar with the somewhat serendipitous event on the September 3, 1928 that led to the penicillin discovery by Fleming (1929). Although the antibacterial properties of mold had been known from ancient times, and researchers before him had come upon the similar observations regarding the antimicrobial activity of Penicillium from time to time ${ }^{2}$, it was his formidable persistency and his belief in the idea that made the difference. For 12 years after his initial observation, A. Fleming was trying to get chemists interested in resolving persisting problems with purification and stability of the active substance and supplied the Penicillium strain to anyone requesting it. He finally abandoned the idea in 1940, but, fortunately, in the same year an Oxford team led by Howard Florey and Ernest Chain published a paper describing the purification of penicillin quantities sufficient for clinical testing (Chain et al., 2005). Their protocol eventually led to penicillin mass production and distribution in 1945 . Fleming's screening method using inhibition zones in lawns of pathogenic bacteria on the surface of agar-medium plates required much less resources than any testing in animal disease models and thus became widely used in mass screenings for antibioticproducing microorganisms by many researchers in academia and industry. Fleming was also among the first who cautioned about the potential resistance to penicillin if used too little or for a too short period during treatment.

Unknown to many, however, is the fact that the first hospital use of a drug that we would name an antibiotic today was the socalled Pyocyanase prepared by Emmerich and Löw (1899) from Pseudomonas aeruginosa (formerly Bacillus pycyaneus). Importantly, Emmerich and Löw noticed that the bacterium as well as the prepared extracts were active against a number of pathogenic bacteria and thus tried to use the extract for treatment of various diseases. As the results of these treatments were not consistent and the preparation itself was quite toxic for humans, the treatment was eventually abandoned. Further investigations confirmed the production of antibiotic substances by Pseudomonas aeruginosa (Hays et al., 1945), which appeared to be the quorum sensing molecules, 2-alkyl-4-quinolones, in this bacterium (Dubern and Diggle, 2008). Another quorum sensing molecule of Pseudomonas aeruginosa, $\mathrm{N}$-(3-oxododecanoyl) homoserine lactone, and its non-enzymatically formed product, 3-(1-hydroxydecylidene)-5-(2-hydroxyethyl)pyrrolidine-2,4-dione, also display potent antibacterial activities (Kaufmann et al., 2005).

The discovery of these first three antimicrobials, Salvarsan, Prontosil, and penicillin, was exemplary, as those studies set up the paradigms for future drug discovery research. The paths, followed

${ }^{2}$ http://en.wikipedia.org/wiki/Discovery_of_penicillin 
by other researchers, resulted in a number of new antibiotics, some of which made their way up to the patient's bedside. The period between the 1950s and 1970s was indeed the golden era of discovery of novel antibiotics classes, with no new classes discovered since then. Therefore, with the decline of the discovery rate, the mainstream approach for the development of new drugs to combat emerging and re-emerging resistance of pathogens to antibiotics has been the modification of existing antibiotics (Chopra et al., 2002).

\section{ANTIBIOTIC RESISTANCE}

Even before the extensive use of penicillin, some observations suggested that bacteria could destroy it by enzymatic degradation (Abraham and Chain, 1940). In general, though, the outlook was more or less optimistic. One of the earlier studies of possible resistance emergence under laboratory conditions concluded that: "Syphilis has now been treated with arsenicals for about 40 years without any indications of an increased incidence of arsenic-resistant infections, and this work gives grounds for hoping that the widespread use of penicillin will equally not result in an increasing incidence of infections resistant to penicillin" (Rollo et al., 1952). Surprisingly, this is still true for T. pallidium (Cha et al., 2004), but not for many other pathogenic bacteria, including the Enterobacteriaceae, which have become resistant not only to the original penicillin but also to semi-synthetic penicillins, cephalosporins, and newer carbapenems (Kumarasamy et al., 2010).

The mortality rates due to multidrug-resistant bacterial infections are high. Each year, about 25,000 patients in the EU die from an infection with the selected multidrug-resistant bacteria (ECDC/ EMEA Joint Working Group, 2009), and more than 63,000 patients in the United States die every year from hospital-acquired bacterial infections ${ }^{3}$. Estimated economic costs due to infections by multidrug-resistant bacteria in the EU result in extra healthcare costs and productivity losses of at least EUR 1.5 billion each year (ECDC/EMEA Joint Working Group, 2009). The annual additional cost of treating hospital-acquired infections from just six species of antibiotic-resistant bacteria was estimated to be at least $\$ 1.3$ billion in 1992 dollars ( $\$ 1.87$ billion in 2006 dollars) - more than the annual spending on influenza ${ }^{3}$.

There are a number of excellent reviews elsewhere describing a variety of antibiotic resistance mechanisms and, within the frames of the bullet-target concept, these mechanisms can be classified as a target or bullet-related. Targets can be: (i) protected by modification (mutations making it insensitive to antibiotic action such as mutations in RNA polymerase conferring resistant to rifampin; (ii) modified by an enzyme (such as methylation of an adenine residue in $23 \mathrm{~S}$ rRNA making it insensitive to macrolides); (iii) replaced (for example, ribosomal protection proteins conferring resistance to tetracyclines); and (iv) protected at cellular or population levels (formation of a protective barrier by secretion, for example, of large amounts of exopolysaccharides). The bullet can be: (i) modified so the efficiency is lost, as in the case of acetylation of aminoglycosides, (ii) destroyed (as the $\beta$-lactam antibiotics by the action of $\beta$-lactamases), and (iii) pumped out from the cell as in efflux pump mechanisms of resistance.

${ }^{3}$ www.extendingthecure.org/report
Recent works in the area of antimicrobials and resistance suggest that not all interactions of bacteria with antibiotics can be explained within the frames of the classical bullet-target concept. For example, a recent work on novel antibiotic resistance mechanism used the "kin selection" concept, since this resistance mechanism operates at the population/system level (Lee et al., 2010). This well-established theory for the macro-organismal world seems also applicable to the microbial world, where a small number of antibiotic-resistant bacteria provide protection for the antibiotic sensitive cells, thus ensuring the survival of the whole population under the antibiotic assault. Moreover, in complex biofilm consortia, the protection against antibiotics is offered to all community members, irrespectively of the kinship, which requires a conceptual framework operating at the system level. Thus the conceptual base of microbe-antibiotic interaction has been broadening beyond the bullet-target model to reflect the complexity of these interactions (Davies et al., 2006; Fajardo and Martínez, 2008; Aminov, 2009; Lee et al., 2010).

\section{RESISTANCE PROBLEM COMPLEXITY}

The current state in the field of antimicrobials, resistance, and chemotherapy is certainly not limited to clinical microbiology as it was in the early years of the antibiotic era. Thus, it is not a single grand challenge; it is rather a complex problem requiring concerted efforts of microbiologists, ecologists, health care specialists, educationalists, policy makers, legislative bodies, agricultural and pharmaceutical industry workers, and the public to deal with. In fact, this should be of everyone's concern, because, in the end, there is always a probability for any of us at some stage to get infected with a pathogen that is resistant to antibiotic treatment. Moreover, even the behavioral patterns, such as hygienic habits or compliance with antibiotic treatment regimens, may have consequences that are not limited only to individual health issues but, on a larger scale, contribute to the interaction with the resistomes around us. In the following sections I will briefly touch upon some of the areas ranging from research to regulations to the cultural patterns that are important in dealing with the challenges of the antimicrobials, resistance, and therapy fields.

\section{IMPROVEMENT OF ANTIMICROBIALS}

This strategy of modification of the existing antimicrobials was initiated (and successfully implemented) during the period, when the rate of discovery of novel drug classes suddenly dropped in the 1970s, and the growing resistance problem enforced researchers to look into the possible modification of the existing arsenal that could confer improved activity, less sensitivity toward resistance mechanisms, and less toxicity (Chopra et al., 2002). Although this approach still successfully provides effective antimicrobials for the market, one of the lessons learned during this arms race is that sooner or later bacteria will acquire resistance to these modified versions as well through the horizontal acquisition of novel resistance mechanisms or rapid molecular evolution of the existing resistances to older antibiotics.

\section{NOVEL ANTIMICROBIALS}

The antibiotic treatment choices for already existing or emerging hard-to-treat multidrug-resistant bacterial infections are limited, resulting in high morbidity and mortality rates. Although there 
are some potential alternatives to antibiotic treatment such as passive immunization (Keller and Stiehm, 2000) or phage therapy (Levin and Bull, 2004; Monk et al., 2010), the mainstream approach relies on the discovery and development of newer, more efficient antibiotics. The vast majority of antimicrobial classes in use today have been isolated in the golden era of antibiotic discovery from a limited number of ecological niches and taxonomic groups, mainly from soil Actinomyces. Further exploration of this ecological niche, coupled with newer technologies such as cell-free assays and highthroughput screening, however, did not produce any novel drug classes in the past $20+$ years. What approaches could be taken to uncover the novel antimicrobials diversity that is potentially suitable for therapeutic applications?

Some possible approaches to tap the novel antimicrobial diversity is the exploration of ecological niches other than soil, such as the marine environment (Hughes and Fenical, 2010; Rahman et al., 2010), borrowing antimicrobial peptides and compounds from animals and plants (Hancock and Sahl, 2006), mimicking the natural lipopeptides of bacteria and fungi (Makovitzki et al., 2006), accessing the uncultivated portion of microbiota through the metagenomic approach (MacNeil et al., 2001), and, finally, the use of the complete synthetic route pioneered during the early years of the antibiotic era. The latter approach becomes dominant in the search for drugs aimed at the newly identified targets in a bacterial cell. Other strategies may include drugs engineered to possess dual target activities, such as a rifamycin-quinolone hybrid antibiotic, CBR-2092 (Robertson et al., 2008).

\section{NEW TARGETS FOR ANTIMICROBIALS}

The vast majority of current antibiotics, even heavily modified, target the same cellular processes as their natural or synthetic predecessors. The range of these targets is limited to the components of translational machinery, cell wall biosynthesis, DNA/ RNA metabolism and some other cellular processes. With the extensive range of genomes sequenced, it becomes possible to implement the idea of a magic bullet in a more elaborate way, with essential targets defined much more precisely at the molecular level. This needs to be complemented by the availability of chemically diverse compound collections to screen for the target/drug combination (Payne et al., 2007). The comparison of metabolic pathways in commensal and pathogenic bacteria and drugs targeting the pathogenic traits may help to identify the novel drug/ target combinations in pathogens and thus the novel paradigm of antimicrobial therapy as targeting virulence (Clatworthy, 2007). Successful implementations of this approach have already been demonstrated in the suppression of an important virulence factor, type III secretion system (Negrea et al., 2007), and in the inhibition of the QseC-mediated activation of virulence gene expression in several pathogens (Rasko et al., 2008). The drugs initially designed for a different purpose may find application as antimicrobials. For example, BPH-652, a phosphonosulfonate, which was previously tested for cholesterol-lowering activity in humans as targeting the enzyme in cholesterol biosynthesis pathway, squalene synthase, is also inhibiting an important enzyme involved in Staphylococcus aureus virulence, dehydrosqualene synthase, and thus may be considered as a candidate drug to control MRSA (Liu et al., 2008).
Other potential targets for intervention in bacterial metabolism include fatty acid biosynthesis (Su and Honek, 2007), cell division (Lock and Harry, 2008), biosynthesis of aminoacyl-tRNAs (Schimmel et al., 1998), quorum sensing (Njoroge and Sperandio, 2009), bacterial two-component signal transduction (Gotoh et al., 2010), and proton motive force (Diacon et al., 2009). Antibiotic resistance mechanisms themselves such as efflux pumps or $\beta$-lactamases can also be targeted to restore the efficacy of antibiotics, which is compromised by the growing resistance problem (Lomovskaya and Bostian, 2006; Bush and Macielag, 2010). It should be noted that, moving along this route, we are cardinally departing from the previously defined classical structural divisions into antibiotic classes. We are only at the beginning here, and not many antibacterial drugs with novel mechanisms of action have entered clinical trials yet, but even at this stage the majority of them do not belong to the previously defined antibiotic classes (Devasahayam et al., 2010).

Also, the intervention strategies aimed not only at the targets but rather at biological networks may help to create new antibacterial therapies (Kohanski et al., 2010a). Combination therapy coupling antibiotics with an antibiotic-enhancing phage, for example, has demonstrated the potential to be a promising antimicrobial intervention (Lu and Collins, 2009).

\section{PREVENTION OF ANTIBIOTIC RESISTANCE}

The main problem we are facing with antibiotic therapy is that after a new antibiotic is introduced, resistance to it will, sooner or later, arise. This scenario has been seen on multiple occasions, and thus there is a continuing race between the discovery and development of new antibiotics and the bacteria that will respond to this selective pressure by the emergence of resistance mechanisms. So how to protect the power of antibiotics and extend their lifespan? There are many factors contributing to the emergence and dissemination of antibiotic resistance and, as mentioned before, the problems require a complex approach.

A significant factor to consider apparently is the use of antibiotics by humans. Not surprisingly, the level of antibiotic-resistant infections strongly correlates with the level of antibiotic consumption (Goossens et al., 2005). There may be requests from patients to prescribe antibiotics when there is no need for them, as in the case of viral infections, and which should be explained to them. Indeed, the lack of knowledge about antibiotic resistance positively correlates with the higher prevalence of resistance (Grigoryan et al., 2007). The important part is also to comply with the drug use regimen, which may be difficult in the case of infections requiring long-term therapy with multiple antibiotics as in the case of TB. The contributing factor to the dissemination of antibiotic resistance, even in the case of absolute compliance, may be the practice of empirical prescription of antibiotics (which accounts for the vast majority of prescriptions). The development of express ABR profiling tests would be quite helpful in the initiation of the most efficient therapy available, avoiding the hurdles associated with a resistant pathogen. In therapy, the use of a recombinant $\beta$-lactamase during intravenous administration of ampicillin may prevent the emergence of antimicrobial resistance in gut microbiota (Tarkkanen et al., 2009).

The situation is different in countries where the sales of antibiotics are inadequately regulated, and antibiotics are available without prescription. In the absence of regulation, the personal decisions on antibiotic purchase and use are governed by cultural and economic 
reasons (Gartin et al., 2010). Self-medication certainly lacks the attributes of a successful therapy, such as proper diagnosis, suitable antibiotic choice, correct usage, compliance, and treatment efficiency monitoring, thus contributing to the mounting resistance problem.

Domesticated animals also get infected and require antibiotic therapy. The agricultural use of antibiotics, however, is not limited exclusively to this use. Antibiotics are also used for the growth promotional and prophylactic purposes in food animals, as well as for a broader and less-targeted treatment in aquaculture and horticulture. The experience of the Scandinavian countries, where the programs of optimal disease preventive management routines and proper use of antimicrobials, combined with the withdrawal of antibiotic growth promoters, were implemented in food animal production, is encouraging. These measures resulted in reduction in the use of antimicrobials and prevented the creation of a relatively favorable situation for antimicrobial resistance (Bengtsson and Wierup, 2006). With the ban of growth promoting antibiotics in 2006, other EU countries have been implementing similar measures to limit the occurrence and dissemination of antibiotic resistance from agricultural sources.

\section{ENVIRONMENTAL RESISTOME}

The history of massive production and use of antibiotics by humans is very short on the evolutionary scale, but even this short-term (albeit large-scale) practice has produced very interesting results demonstrating the interminable adaptive capabilities of bacteria, which allow them to withstand massive antibiotic insults and generate some formidable examples of hard-to-treat infections that we call "superbugs." Although no broad baseline data collection on antibiotic resistance genes has been performed at the onset of antibiotic use, recent studies suggest that the most likely source of these genes is the environmental antibiotic resistome (Martínez, 2008; Wright, 2010). The functional role of antimicrobials and the corresponding resistance genes in natural ecosystems is hypothesized as a signaling/regulatory rather than a bullet/target relationship (Davies et al., 2006; Fajardo and Martínez, 2008; Aminov, 2009). Confirmatory to this suggestion are also the other therapeutic properties of antimicrobials, well beyond the initial range of use as anti-infective agents (Griffin et al., 2010). Bacteria do not respect the boundaries of ecological compartments, and there is always a continuous flow by genetic information between different ecological compartments. Once the potential antibiotic resistance genes enter, even in small numbers or low frequencies, into the commensal/pathogenic human/animal microbiota, the antibiotic selection immediately leads to the amplification and dissemination of these genes. Indeed, there is some evidence on the environmental origin of some clinically relevant resistance genes (Wright, 2010).

The predecessor/ancestral genes for antibiotic resistance are not necessarily the genes conferring resistance per se in natural ecosystems. The recently emerged resistance to synthetic antibiotics of the quinolone class is mediated by the qnr genes that have been acquired from aquatic bacteria (Poirel et al., 2005). It was suggested that the original function of one of its homologs, MfpA, is providing DNA topological assistance when needed, and maintaining a condensed chromosome and preventing undesired topological changes during periods of replicative senescence (Hegde et al., 2005). In this scenario of quinolone resistance emergence, the enzyme involved in DNA metabolism in environmental bacteria also happened to be protecting against this synthetic antibiotic, and, once the encoding gene entered into the human/animal microbiota on a mobile element, a strong selective pressure led to its amplification and dissemination into the commensal and pathogenic microbiota (Aminov and Mackie, 2007).

Another important aspect is the release of antibiotics and the corresponding pre-selected and amplified antibiotic resistance gene pool from the human and animal ecological compartments back into the environment (Chee-Sanford et al., 2009). What are the consequences of this? Does the resulting multidrug combination in the environment accelerate the evolution toward antimicrobial resistance (Hegreness et al., 2008)? What are the consequences of the presence of sublethal concentration antibiotics in the environment (Kohanski et al., 2010b)? What is the impact of the environmental stresses, such as, for example, the SOS response-inducing UV radiation, on the horizontal dissemination of antibiotic resistance genes (Beaber et al., 2004)? What is the rate of decay of the released antibiotic resistance genes in the environment, given the improved survival strategies of mobile genetic elements (de la Cueva-Méndez and Pimentel, 2007)? Could the environment provide a broader playground for the mobile antibiotic resistance encoding elements to promote their own diversity (Garriss et al., 2009)? And what are the chances for antibiotic resistance genes to re-enter the human and animal food chain? There are pressing needs to answer these questions to build the broader strategies that would help to preserve the power of antibiotics.

\section{CONCLUSIONS}

Albeit very brief, both on the global evolutionary and human history scales, the antibiotics era went through many ups and downs, providing us valuable lessons on many aspects of how the microbial world around us functions. The discovery and use of antibiotics, antibiotic resistance markers, and mobile elements such plasmids were at the foundation of genetic engineering and molecular biology that eventually resulted in spectacular successes of the human genome and other sequencing projects. These tools were also indispensable for shaping modern biotechnology ranging from the production of recombinant proteins to construction of entire metabolic pathways. Microorganisms, however, use the very same (and probably some additional but still unidentified) natural mechanisms to protect themselves against the massive antibiotic assaults continuously launched by the humankind from the time of discovery of antibiotics. Although the majority of infections were placed under control, this equilibrium in the arm race is fragile, since during the almost four billion years of evolution the microbial world has accumulated an enormous diversity of metabolic and protective mechanisms than can be mobilized in response to a strong selection. We need to learn to be more precise in targeting the pathogens and limit the indiscriminate use of antimicrobials and other practices that accelerate the emergence of novel resistance mechanisms. Investigation of the microbial world around us for potential mechanisms of antibiotic resistance and dissemination may help to design the early warning and preventive measures to sustain the efficacy of antimicrobials and chemotherapy.

\section{ACKNOWLEDGMENT}

I thank the Scottish Government Rural and Environment Research and Analysis Directorate for support. 


\section{REFERENCES}

Abraham, E. P., and Chain, E. (1940). An enzyme from bacteria able to destroy penicillin. Nature 146, 837.

Aminov, R. I. (2009). The role of antibiotics and antibiotic resistance in nature. Environ. Microbiol. 11, 2970-2988.

Aminov, R. I., and Mackie, R. I. (2007). Evolution and ecology of antibiotic resistance genes. FEMS Microbiol. Lett. 271, 147-161.

Armelagos, G. J. (1969). Disease in ancient Nubia. Science 163, 225-258.

Bassett, E. J., Keith, M. S., Armelagos, G. J., Martin, D. L., and Villanueva, A. R. (1980). Tetracycline-labeled human bone from ancient Sudanese Nubia (A.D. 350). Science 209, 1532-1534.

Beaber, J. W., Hochhut, B., and Waldor M. K. (2004). SOS response promotes horizontal dissemination of antibiotic resistance genes. Nature 427, 72-74.

Bengtsson, B., and Wierup, M. (2006). Antimicrobial resistance in Scandinavia after ban of antimicrobial growth promoters. Anim. Biotechnol. 17, 147-156.

Bush, K., and Macielag, M. J. (2010). New $\beta$-lactam antibiotics and $\beta$-lactamase inhibitors. Expert Opin. Ther. Pat. 20, 1277-1293.

Cha, J. Y., Ishiwata, A., and Mobashery, S. (2004). A novel $\beta$-lactamase activity from a penicillin-binding protein of Treponema pallidum and why syphilis is still treatable with penicillin. J. Biol. Chem. 279, 14917-14921.

Chain, E., Florey, H. W., Gardner, A. D., Heatley, N. G., Jennings, M. A., OrrEwing, J., and Sanders, A. G. (2005). The classic: penicillin as a chemotherapeutic agent. 1940. Clin. Orthop. Relat. Res. 439, 23-26.

Chee-Sanford, J. C., Mackie, R. I., Koike, S., Krapac, I. G., Lin, Y. F., Yannarell, A. C., Maxwell, S., and Aminov, R. I. (2009). Fate and transport of antibiotic residues and antibiotic resistance genes following land application of manure waste. J. Environ. Qual. 38, 1086-1108.

Chopra, I., Hesse, L., and O'Neill, A. (2002). "Discovery and development of new anti-bacterial drugs," in Pharmacochemistry Library, Vol. 32, Trends in Drug Research III, ed. H. van der Goot (Amsterdam: Elsevier), 213-225.

Clatworthy, A. E., Pierson, E., and Hung, D. T. (2007). Targeting virulence: a new paradigm for antimicrobial therapy. Nat. Chem. Biol. 3, 541-548.

Cook, M., Molto, E., and Anderson, C. (1989). Fluorochrome labelling in Roman period skeletons from Dakhleh Oasis, Egypt. Am. J. Phys. Anthropol. 80, 137-143.

Cui, L., and Su, X. Z. (2009). Discovery, mechanisms of action and combination therapy of artemisinin. Expert Rev. Anti. Infect. Ther. 7, 999-1013.

Davies, J., Spiegelman, G. B., and Yim, G. (2006). The world of subinhibitory antibiotic concentrations. Curr. Opin. Microbiol. 9, 445-453.

de la Cueva-Méndez, G., and Pimentel, B. (2007). Gene and cell survival: lessons from prokaryotic plasmid R1. EMBO Rep. 8, 458-464.

Devasahayam, G., Scheld, W. M., and Hoffman, P.S. (2010). Newer antibacterial drugs for a new century. Expert Opin. Investig. Drugs 19, 215-234.

Diacon, A. H., Pym, A., and Grobusch, M. (2009). The diarylquinoline TMC207 for multidrug-resistant tuberculosis. N. Engl. J. Med. 360, 2397-2405.

Domagk, G. (1935). Ein Beitrag zur Chemotherapie der bakteriellen Infektionen. Dtsch. Med. Wochenschr. $61,250$.

Dubern, J. F., and Diggle, S. P. (2008) Quorum sensing by 2-alkyl-4-quinolones in Pseudomonas aeruginosa and other bacterial species. Mol Biosyst 4, 882-888.

Ehrlich, P., and Hata, S. (1910). Die Experimentelle Chemotherapie der Spirilosen. Berlin: Julius Springer.

Emmerich, R., and Löw, O. (1899). Bakteriolytische enzyme als Ursache der erworbenen Immunität und die Heilung von Infectionskrankheiten durch dieselben. Z. Hyg. 31, 1-65.

Enne, V.I., Bennett, P.M., Livermore, D.M., and Hall, L. M. (2004). Enhancement of host fitness by the sul2-coding plasmid p9123 in the absence of selective pressure. J.Antimicrob. Chemother. 53 958-963.

European Centre for Disease Prevention and Control/European Medicines Agency Joint Working Group (ECDC/EMEA). (2009). The Bacterial Challenge: Time to React. Available at www.ecdc.europa.eu/en/publications/Publications/0909_TER_The Bacterial Challenge Time to React. pdf.

Fajardo, A., and Martínez, J. L. (2008). Antibiotics as signals that trigger specific bacterial responses. Curr. Opin. Microbiol. 11, 161-167.

Falkinham, J. O. 3rd, Wall, T. E., Tanner, J. R., Tawaha, K., Alali, F. Q., Li, C., and Oberlies, N. H. (2009). Proliferation of antibiotic-producing bacteria and concomitant antibiotic production as the basis for the antibiotic activity of Jordan's red soils. Appl. Environ. Microbiol. 75, 2735-2741.

Fevre, C., Jbel, M., Passet, V., Weill, F. X. Grimont, P. A., and Brisse, S. (2005) Six groups of the OXY $\beta$-lactamase evolved over millions of years in Klebsiella oxytoca. Antimicrob. Agents Chemother. 49, 3453-3462.
Fleming, A. (1929). On antibacterial action of culture of Penicillium, with special reference to their use in isolation of B. influenzae. Br. J. Exp. Pathol 10, 226-236.

Garau, G., Di Guilmi, A. M., and Hall, B. G. (2005). Structure-based phylogeny of the metallo-beta-lactamases. Antimicrob. Agents Chemother. 49 2778-2784.

Garriss, G., Waldor, M. K., and Burrus, V. (2009). Mobile antibiotic resistance encoding elements promote their own diversity. PLoS Genet. 5, e1000775. doi: 10.1371/journal.pgen.1000775

Gartin, M., Brewis, A. A., and Schwartz, N. A. (2010). Nonprescription antibiotic therapy: cultural models on both sides of the counter and both sides of the border. Med. Anthropol. Q. 24, 85-107.

Goossens, H., Ferech, M., Vander Stichele, R., Elseviers, M., and ESAC Project Group. (2005). Outpatient antibiotic use in Europe and association with resistance: a cross-national database study. Lancet 365, 579-587.

Gotoh, Y., Eguchi, Y., Watanabe, T. Okamoto, S., Doi, A., and Utsumi, R. (2010). Two-component signal transduction as potential drug targets in pathogenic bacteria. Curr. Opin. Microbiol. 13, 232-239.

Griffin, M. O., Fricovsky, E., Ceballos, G. and Villarreal, F. (2010). Tetracyclines: a pleitropic family of compounds with promising therapeutic properties. Review of the literature. Am. J. Physiol. Cell Physiol. 299, C539-C548.

Grigoryan, L., Burgerhof, J. G., Degener, J. E., Deschepper, R., Lundborg, C. S., Monnet, D. L., Scicluna, E. A., Birkin, J., Haaijer-Ruskamp, F. M., and SAR Consortium. (2007). Attitudes, beliefs and knowledge concerning antibiotic use and self-medication: a comparative European study. Pharmacoepidemiol. Drug. Saf. 16, 1234-1243.

Hall, B. G., and Barlow, M. (2004) Evolution of the serine beta-lactamases: past, present and future. Drug Resist. Updat. 7, 111-123.

Hancock, R. E., and Sahl, H. G. (2006) Antimicrobial and host-defense peptides as new anti-infective therapeutic strategies. Nat. Biotechnol. 24, 1551-1557.

Hays, E. E., Wells, I. C., Katzman, P. A. Cain, C. K., Jacobs, F. A., Thayer, S. A., Doisy, E. A., Gaby, W. L., Roberts E. C., Muir, R. D., Carroll, C. J., Jones, L. R., and Wade, N. J. (1945). Antibiotic substances produced by Pseudomonas aeruginosa. J. Biol. Chem. 159, 725-750.

Hegde, S. S., Vetting, M.W., Roderick, S.L., Mitchenall, L. A., Maxwell, A., Takiff, H. E., and Blanchard, J. S. (2005). A fluoroquinolone resistance protein from Mycobacterium tuberculosis that mimics DNA. Science 308 , 1480-1483.

Hegreness, M., Shoresh, N., Damian, D. Hartl, D., and Kishony, R. (2008). Accelerated evolution of resistance in multidrug environments. Proc. Nat Acad. Sci. U.S.A. 105, 13977-13981.

Hughes, C. C., and Fenical, W. (2010). Antibacterials from the sea. Chemistry $16,12512-12525$

Kaufmann, G. F., Sartorio, R., Lee, S. H., Rogers, C. J., Meijler, M. M., Moss, J.A., Clapham, B., Brogan, A. P., Dickerson, T. J., and Janda, K. D. (2005). Revisiting quorum sensing: discovery of additional chemical and biological functions for 3-oxo- $\mathrm{N}$-acylhomoserine lactones. Proc. Natl. Acad. Sci. U.S.A. 102, 309-314.

Keller, M. A., and Stiehm, E. R. (2000). Passive immunity in prevention and treatment of infectious diseases. Clin. Microbiol. Rev. 13, 602-614.

Kobayashi, T., Nonaka, L., Maruyama, F., and Suzuki, S. (2007). Molecula evidence for the ancient origin of the ribosomal protection protein that mediates tetracycline resistance in bacteria. J. Mol. Evol. 65, 228-235.

Kohanski, M.A., Dwyer, D. J., and Collins, J. J. (2010a). How antibiotics kill bacteria: from targets to networks. Nat Rev. Microbiol. 8, 423-435.

Kohanski, M. A., DePristo, M. A., and Collins, J. J. (2010b). Sublethal antibiotic treatment leads to multidrug resistance via radical-induced mutagenesis. Mol. Cell 37, 311-320.

Kumarasamy, K. K., Toleman, M.A., Walsh, T. R., Bagaria, J., Butt, F., Balakrishnan, R., Chaudhary, U., Doumith, M., Giske, C. G., Irfan, S., Krishnan, P., Kumar, A. V., Maharjan, S., Mushtaq, S., Noorie, T., Paterson, D. L., Pearson, A., Perry, C., Pike, R., Rao, B., Ray, U., Sarma, J. B., Sharma, M., Sheridan, E., Thirunarayan, M. A., Turton, J., Upadhyay, S., Warner, M., Welfare, W., Livermore, D. M., and Woodford N. (2010). Emergence of a new antibiotic resistance mechanism in India, Pakistan, and the UK: a molecular, biological, and epidemiological study. Lancet Infect. Dis. 10, 597-602.

Lee, H.H., Molla, M. N., Cantor, C. R., and Collins, J. J. (2010). Bacterial charity work leads to population-wide resistance. Nature 467, 82-85.

Levin, B. R., and Bull, J. J. (2004). Population and evolutionary dynamics of phage therapy. Nat. Rev. Microbiol. 2, 166-173.

Liu, C. I., Liu, G. Y., Song, Y., Yin, F., Hensler, M. E., Jeng, W. Y., Nizet, V., Wang, A. H., and Oldfield, E. (2008). A cholesterol biosynthesis inhibitor blocks Staphylococcus aureus virulence. Science 319, 1391-1394. 
Lloyd, N. C., Morgan, H. W., Nicholson, B. K., and Ronimus, R. S. (2005). The Composition of Ehrlich's Salvarsan: resolution of a century-old debate. Angew. Chem. Int. Ed. 44, 941-944.

Lock, R. L., and Harry, E. J. (2008). Celldivision inhibitors: new insights for future antibiotics. Nat. Rev. Drug Discov. 7, 324-338.

Lomovskaya, O., and Bostian, K.A. (2006). Practical applications and feasibility of efflux pump inhibitors in the clinic--a vision for applied use. Biochem. Pharmacol. 71, 910-908.

Lu, T. K., and Collins, J. J. (2009) Engineered bacteriophage targeting gene networks as adjuvants for antibiotic therapy. Proc. Natl. Acad. Sci. U.S.A. 106, 4629-4633.

MacNeil, I. A., Tiong, C. L., Minor, C., August, P.R., Grossman, T.H., Loiacono, K.A., Lynch, B.A., Phillips, T., Narula, S., Sundaramoorthi, R., Tyler,A.,Aldredge, T., Long, H., Gilman, M., Holt, D., and Osburne, M.S. (2001). Expression and isolation of antimicrobial small molecules from soil DNA libraries. J. Mol. Microbiol. Biotechnol. 3, 301-308.

Mahoney, J., Arnold, R., and Harris, A. (1943). Penicillin treatment of early syphilis. A preliminary report. Verer. Dis. Inform. 24, 355-357.

Makovitzki, A., Avrahami, D., and Shai, Y. (2006). Ultrashort antibacterial and antifungal lipopeptides. Proc. Natl. Acad. Sci. U.S.A. 103, 15997-16002.

Martínez, J. L. (2008). Antibiotics and antibiotic resistance genes in natural environments. Science 321, 365-367.

Monk, A. B., Rees, C. D., Barrow, P., Hagens, S., and Harper, D. R. (2010).
Bacteriophage applications: where are we now? Lett. Appl. Microbiol. 51, 363-369.

Negrea, A., Bjur, E., and Ygberg, S. E. (2007). Salicylidene acylhydrazides that affect type III protein secretion in Salmonella enterica serovar typhimurium. Antimicrob. Agents Chemother. 51, 2867-2876.

Nelson, M. L., Dinardo, A., Hochberg, J., and Armelagos, G. J. (2010). Brief communication: mass spectroscopic characterization of tetracycline in the skeletal remains of an ancient population from Sudanese Nubia 350-550 CE. Am. J. Phys. Anthropol. 143, 151-154.

Njoroge, J., and Sperandio, V. (2009). Jamming bacterial communication: new approaches for the treatment of infectious diseases. EMBO Mol. Med. 1, 201-210.

Payne, D. J., Gwynn, M. N., Holmes, D. J., and Pompliano, D. L. (2007). Drugs for bad bugs: confronting the challenges of antibacterial discovery. Nat. Rev. Drug Discov. 6, 29-40.

Poirel, L., Rodriguez-Martinez, J. M., Mammeri, H., Liard, A., and Nordmann, P. (2005). Origin of plasmid-mediated quinolone resistance determinant QnrA. Antimicrob. Agents Chemother. 49, 3523-3525.

Rahman, H., Austin, B., Mitchell, W. J. Morris, P. C., Jamieson, D. J., Adams, D. R., Spragg, A. M., and Schweizer, M. (2010). Novel anti-infective compounds from marine bacteria. Mar. Drugs 8, 498-518.

Rasko, D. A., Moreira, C. G., Li de, R., Reading, N. C., Ritchie, J. M., Waldor, M. K., Williams, N., Taussig, R., Wei, S.
Roth, M., Hughes, D. T., Huntley, J. F., Fina, M.W., Falck, J. R., and Sperandio, V. (2008). Targeting QseC signaling and virulence for antibiotic development. Science 321, 1078-1080.

Robertson, G. T., Bonventre, E. J., and Doyle, T. B. (2008). In vitro evaluation of CBR-2092, a novel rifamycinquinolone hybrid antibiotic: studies of the mode of action in Staphylococcus aureus. Antimicrob. Agents Chemother. 52, 2313-2323.

Rollo, I. M., Williamson, J., and Plackett, R. L. (1952). Acquired resistance to penicillin and to neoarsphenamine in Spirochaeta recurrentis. Br. J. Pharmacol. Chemother. 7, 33-41.

Schimmel, P., Tao, J., and Hill, J. (1998) Aminoacyl tRNA synthetases as targets for new anti-infectives. FASEB J. 12, 1599-1609.

Sobell, H. M. (1985). Actinomycin and DNA transcription. Proc. Natl. Acad. Sci. U.S.A. 82, 5328-5331.

Song, J. S., Jeon, J. H., Lee, J. H., Jeong, S. H., Jeong, B. C., Kim, S. J., Lee, J. H., and Lee, S. H. (2005). Molecular characterization of TEM-type betalactamases identified in cold-seep sediments of Edison Seamount (south of Lihir Island, Papua New Guinea). J. Microbiol. 43, 172-178.

Su, Z., and Honek, J. F. (2007). Emerging bacterial enzyme targets. Curr. Opin. Investig. Drugs 8, 140-149.

Tarkkanen, A. M., Heinonen, T., and Jogi, R. (2009). P1A recombinant $\beta$-lactamase prevents emergence of antimicrobial resistance in gut microflora of healthy subjects during intravenous administration of ampicillin.
Antimicrob. Agents Chemother. 53, 2455-2462.

Walsh, C. T. (2003). Antibiotics: Actions, Origins, and Resistance. Washington, DC: ASM Press

Wong, R. W., Hägg, U., Samaranayake, L., Yuen, M. K., Seneviratne, C. J., and Kao, R. (2010). Antimicrobial activity of Chinese medicine herbs against common bacteria in oral biofilm. A pilot study. Int. J. Oral Maxillofac. Surg. 39, 599-605.

Wright, G.D. (2010).Antibiotic resistance in the environment: a link to the clinic? Curr. Opin. Microbiol.13, 589-594.

Conflict of Interest Statement: The author declares that the research was conducted in the absence of any commercial or financial relationships that could be construed as a potential conflict of interest.

Received: 29 September 2010; paper pending published: 29 October 2010; accepted: 17 November 2010; published online: 08 December 2010

Citation: Aminov RI (2010) A brief history of the antibiotic era: lessons learned and challenges for the future. Front. Microbio. 1:134. doi: 10.3389/fmicb.2010.00134 This article was submitted to Frontiers in Antimicrobials, Resistance and Chemotherapy, a specialty of Frontiers in Microbiology.

Copyright (c) 2010 Aminov. This is an open-access article subject to an exclusive license agreement between the authors and the Frontiers Research Foundation, which permits unrestricted use, distribution, and reproduction in any medium, provided the original authors and source are credited. 